\title{
VAlidation Study OF Path Loss Models ON WIMAX AT 2.6 GHZ FREQUENCY BAND IN SUBURBAN ENVIRONMENT FOR CELL SIZE PlanNing
}

\author{
Pratibha Maina $^{1}$,Gopal Chandra Manna ${ }^{2}$, Namrata Sahayam ${ }^{3}$ \\ ${ }^{1,3}$ Dept, of Electronics and Communication Engg., Government Engineering College, \\ Jabalpur, M.P. India \\ ${ }^{2}$ Inspection Circle, BSNL, Jabalpur, M.P.India
}

\begin{abstract}
The radio wave propagation in form of path loss model plays very significant role in planning of any wireless communication network. Measurement of signal strength of OFDM driven WiMAX technology at $2.6 \mathrm{GHz}$ band is taken in Suburban Town of India. The results are analyzed and compared with Empirical path loss models such as Hata-Okumura, Modified Hata and COST-231Hata. COST-231 model shows highest path loss for suburban environment. These analyzed results establish that COST-231 model is suitable for suburban environment also. Threshold RSSI estimates cell coverage probability in the area.
\end{abstract}

\section{KEYWORDS}

OFDM, WiMAX, IEEE 802.16, path loss exponent, Rayleigh fading, RSSI, CINR

\section{INTRODUCTION}

Mobile WiMAX offers full mobility cellular networks at high speeds. It is based on OFDM technology

Radio wave propagation depends on various factors like reflection, refraction, diffraction etc. This results in multipath fading at the received location. The fading is vary with time slowly as well as with distance from transmitter. If we consider an Omni-directional transmitter, we can presume that the signal strength along the circumference of a fixed radius around the transmitter shall be same but actually it is not. Scientists have calculated Cell edge probability and area coverage probability based on parameters like initial path loss, path loss exponent $(\gamma)$ and Rayleigh fading factor $(\sigma)$. Jakes graph is usually deployed for prediction of cell radius. Now, commercially available planning tools are deployed for estimation of coverage which includes clutter diagram and a suitable prediction model. Base transceiver station location is plotted on the predicted coverage map plot. Present paper uses WiMAX network operating at a frequency of 2.6 $\mathrm{GHz}$ for the study of path loss and compare with existing propagation models. Two rural locations of Rajasthan were carried out for studies with BTS height of 40m during the months of November 2009 to February 2010. It was a hilly area and mostly covered by dense trees [1]. For GSM, studies were carried out at dense city like Kolkata and medium to small towns like Raipur, Jabalpur, Katni, Jagdalpur etc of India during 2006 to 2009[2]. To estimate the coverage of WiMAX based on IEEE 802.16d at Kalyani, a suburban area of Kolkata City, a study was carried out in 2007. Measurements were taken for rooftop antennas on line of sight (LoS) condition up to

DOI : 10.5121/ijngn.2014.6202 
International Journal of Next-Generation Networks (IJNGN) Vol.6, No.2, June 2014

$4 \mathrm{~km}$ and backhaul throughput capacity of $2 \mathrm{mbps}$ due to practical limitations. The throughput was observed full and signal quality was found adequate [3].

Kariapatti in Tamil Nadu, has mostly suburban terrain profile. Present study on WiMAX based on IEEE 802.16e recommendation was conducted at suburban location of Tamil Nadu. The observations were taken in the Evening time; however, sky was clear during the period of observations. The area covers single storey buildings with medium height trees and few populated area. The study measured all the above components for effective service and leads to estimate values of various communication parameters essential for estimation of coverage.

In this paper, two optimized models are used namely Modified Hata model and COST-231 Hata model to predict path loss for WiMAX in $2640 \mathrm{MHz}$ to $2650 \mathrm{MHz}$.The COST-231 model showed best agreement with the measured path loss in terms of path loss exponent as compared to Hata model and Modified Hata model in estimating the path loss in the $2640 \mathrm{MHz}$ to $2650 \mathrm{MHz}$.

Section 2. discusses various propagation models based on which WiMAX coverage is predicted and a statistical approach for gross estimation of path loss exponent and fading component. The various studies already conducted on several mobile communication technologies and results obtained has been stated in Section 3. Base station setup, Subscriber Station location arrangements and methodology of data collection has been elaborated in Section 4. Processing of data and results obtained has been given in Section 5 . followed by discussions and conclusion has been drawn in Section 6.

\section{PATH LOSS MODELS}

Path loss is defined as the difference between transmitted power and received power,

Path loss $=$ Transmitted power + gain - Received power

Here, we have used the transmitting power of $40 \mathrm{dbi}$ and transmitting antenna gain of $17 \mathrm{dbi}$.

Path loss is the reduction in signal strength when it propagates from Tx to Rx. Various parameters reduces the signal strength such as height of antenna, distance between Tx and Rx, obstacles such as trees, buildings,etc. transmitted power and antenna gain.

A general model which includes path loss exponent and shadow fading factor is given as

$$
\operatorname{PL}(\mathrm{dB})=\operatorname{PL}\left(\mathrm{d}_{0}\right)+10 \gamma \log \left(\mathrm{d} / \mathrm{d}_{0}\right)+\sigma
$$

Where PL $\left(\mathrm{d}_{0}\right)$ the intercept, $\gamma$ is the slope and $\sigma$ is the standard deviation of received signals [5].Losses are measured in $\mathrm{dBm}$ and $\mathrm{d}$ is in meters.

RSSI is the received signal strength on the receiver side. It is the indication of received power level. On the basis of RSSI values one can obtain the communication range of base station. A plot of Received Signal Strength Indicator (RSSI) with distance from transmitter may be considered as radial coverage. According to Jake's graph, if $P x_{0}(\mathrm{R})$ is the probability of radial coverage where received signal threshold is $x_{0} \mathrm{dBm}$ at distance $\mathrm{R}$, then

$$
P x_{0}(R)=\frac{1}{2}-\frac{1}{2} \operatorname{erf}\left(\frac{x_{0}-\bar{x}}{\sigma \sqrt{2}}\right)
$$

Where, $\bar{x}$ is the mean of the received signal strength. From Jake's graph, the area coverage probability for a radius coverage probability can be obtained for the corresponding radius. 


\subsection{Hata Model}

Okumura Hata model is widely used for voice coverage in below $1500 \mathrm{MHz}$ range and the same has been deployed with modification for prediction of WiMAX coverage which works in 2500 $\mathrm{MHz}$ and $3500 \mathrm{MHz}$ band. There are three different environments namely urban, suburban and rural environment. Hata model has different path loss model for each environment. This model can be used for both point to point and broadcast transmissions[8]. For urban environment path loss is given as:

$$
\mathrm{PL}(\mathrm{U})=69.55+26.16 \log (\mathrm{f})-13.82 \log \left(\mathrm{h}_{\mathrm{t}}\right)-\mathrm{ah}_{\mathrm{m}}+44.9-6.55 \log \left(\mathrm{h}_{\mathrm{t}}\right) \cdot \log (\mathrm{d})
$$

Where,

$\mathrm{PL}=$ path loss in $\mathrm{dB}$,

$\mathrm{f}=$ frequency in $\mathrm{MHz}$,

$\mathrm{h}_{\mathrm{t}}=$ height of the transmitting antenna in meters,

$\mathrm{ah}_{\mathrm{m}}=$ HATA correction factor,

$\mathrm{d}=$ distance in $\mathrm{km}$

For Sub-urban environment,

$$
\mathrm{PL}(\mathrm{SU})=\mathrm{PL}(\mathrm{U})-5.4-2\left[\log _{10}\left(\frac{f}{28}\right)\right]^{2}
$$

For rural environment,

$$
\mathrm{PL}(\mathrm{R})=\mathrm{PL}(\mathrm{U})+18.33 \log _{10}(\mathrm{f})-4.78\left[\log _{10}(\mathrm{f})\right]^{2}-\mathrm{K}
$$

Where, K ranges from 35.94 to 40.94 for countryside and desert respectively.

For small to medium cities and for large cities the correction factor $\mathrm{ah}_{\mathrm{m}}$ is given by

$$
\begin{aligned}
& \mathrm{ah}_{\mathrm{m}}=\left(1.1 \log _{10}(\mathrm{f})-0.7\right) \mathrm{h}_{\mathrm{r}}-\left(1.56 \log _{10}(\mathrm{f})-0.8\right) \\
& \mathrm{ah}_{\mathrm{m}}=3.2\left(\log _{10} 11.75 . \mathrm{h}_{\mathrm{r}}\right)^{2}-4.97
\end{aligned}
$$

\subsection{Modified HATA Model}

Modified Hata model is the modification of Hata model. It is modified for making it suitable for given environment [8].

For urban environment,

$$
\begin{aligned}
\mathrm{PL}(\mathrm{U}) & =69.55+26.16 \log _{10}(\mathrm{f})-13.82 \log \left(\mathrm{h}_{\mathrm{t}}\right)-\mathrm{ah}_{\mathrm{m}} \\
+ & 44.9-6.55 \log \left(\mathrm{h}_{\mathrm{t}}\right) \cdot \log (\mathrm{d})+\mathrm{Cm}(\mathrm{U})
\end{aligned}
$$

For sub-urban environment,

$$
\mathrm{PL}(\mathrm{SU})=\mathrm{PL}(\mathrm{U})-5.4-2\left[\log _{10}\left(\frac{\mathrm{f}}{28}\right)\right]^{2}
$$

For rural environment,

$$
\mathrm{PL}(\mathrm{R})=\mathrm{PL}(\mathrm{U})-4.78\left[\log _{10}(\mathrm{f})\right]^{2}+18.33 \log _{10}(\mathrm{f})-\mathrm{Cm}(\mathrm{R})
$$

Where, $\mathrm{Cm}(\mathrm{U})$ and $\mathrm{Cm}(\mathrm{R})$ are the correction factors for urban and rural environments and taken as 12 and 29 respectively. 
International Journal of Next-Generation Networks (IJNGN) Vol.6, No.2, June 2014

\subsection{COST-231 HATA Model}

COST-231 has also been used for calculation of path loss with correction factor $\mathrm{Cm}=0$ as applicable for sub-urban centers with medium tree density [4]. COST-231 is an extended form of Hata model and used in the frequency range of 1500-2000 MHz. Here it is used from $2300 \mathrm{MHz}$ to $2600 \mathrm{MHz}$ for WiMAX system. The path loss for this model is calculated as:

$\mathrm{PL}(\mathrm{dB})=46.33+\left(44.9-6.55 \log _{10}\left(\mathrm{~h}_{\mathrm{t}}\right)\right) \log _{10}(\mathrm{~d})+33.9 \log _{10}(\mathrm{f})-13.82 \log _{10}\left(\mathrm{~h}_{\mathrm{t}}\right)-\mathrm{ah}_{\mathrm{m}}+\mathrm{Cm}$

Where,

$\mathrm{f}=$ frequency in $\mathrm{MHz}$,

$\mathrm{d}=$ distance between BTS and receiving antennae in $\mathrm{km}$

$\mathrm{h}_{\mathrm{t}}=$ transmitting antenna height in meters

The correction factor, $\mathrm{Cm}$ is given as $\mathrm{Cm}(\mathrm{U})=3 \mathrm{~dB}$ and $\mathrm{Cm}(\mathrm{SU})=0 \mathrm{~dB}$ respectively

The correction factor $\mathrm{ah}_{\mathrm{m}}$ for urban and suburban environments are defined as

$$
\begin{aligned}
& \mathrm{ah}_{\mathrm{m}}=3.2\left(\log _{10}\left(11.75 \mathrm{~h}_{\mathrm{r}}\right)\right)^{2}-4.97 \\
& \mathrm{ah}_{\mathrm{m}}=\left(1.1 \log _{10}(\mathrm{f})-0.7\right) \mathrm{h}_{\mathrm{r}}-\left(1.56 \log _{10}(\mathrm{f})-0.8\right)
\end{aligned}
$$

Where, $h_{r}$ is the receiving antenna height in meters.

\section{RELATED WORKS}

A comparison were made among different environments of Bangladesh using different path loss models at $2.5 \mathrm{GHz}$ frequency band where Free Space Path loss model referred for LOS condition and SUI model showed lowest path loss and ECC-33 model showed highest path loss for NLOS condition [6]. During 2010, optimization of HATA propagation prediction model in suburban area was conducted in Malaysia by R. Mardeni and K. F. Kwan [7]. Similar study was conducted at the sub-urban area of Kalyani, Kolkata for LOS and NLOS conditions where terrain is mostly flat and building height is averaged at $7 \mathrm{~m}$ [3]. Modified Hata model have been used for path loss calculations which has proven more appropriate for GSM cellular communication [8]. Path loss modeling for vehicle-to-vehicle communication were carried out for four different environments e.g. highway, rural, urban, suburban. Measurement was conducted in Lund, Sweden, during January 2011[9]. Different propagation models that would be used for Long Term Evolution (LTE), a comparison were made among them and SUI showed lowest path loss for all terrains[10]. A pilot project is being conducted at the IRT (Institute fur Rundfunk technik) to test the digital video broadcasting ability of both fixed and mobile WiMAX at Munich city during 2009[11]. SUIT (Scalable, Ultra-fast and Interoperable Interactive Television) conducted field trial at Aveiro-Portugal for mobile WiMAX over $10 \mathrm{MHZ}$ bandwidth and at speed up to 140 $\mathrm{kmph}$ and measured throughput in sub-urban city environment for both unicast and multicast mode during 2009[12]. In comparison to ECC-33 model, Hata Okumura and COST-231 models showed the highest probability for same parameters. In addition the received signal strength (RSS) of base station with noise and without noise is calculated for the same area by Mukesh Kumar, Vijay Kumar, Suchika Malik during during February 2012[13]. Radio Measurements in the WiMAX Band of $2.3 \mathrm{GHz}$ for different antenna heights, was conducted in the urban coastal region of Mumbai during June 2012 by Chhaya Dalela [14]. VoIP and video streaming performance was measured over mobile WiMAX testbed deployed at the campus of Institute Telecom SudParis during the period May 2012[15].

Study of all above reference reveals that there is very little approach to evaluate $\gamma$ for Indian environment. Further there is no installation which covers OFDM at $2.3 \mathrm{GHz}$ range. In the present study, OFDM at $2.6 \mathrm{GHz}$ band has been used and $\gamma$ has been calculated. The path loss 
International Journal of Next-Generation Networks (IJNGN) Vol.6, No.2, June 2014

model thus obtained may be scaled to estimate path loss at a lower frequency range of $2.3 \mathrm{GHz}$ band. The results for both the bands are nearly same.

\section{STUDY SETUP AND OBSERVATION}

\subsection{Base Station}

Base Station is installed at Kariapatti in Tamil Nadu province of India. Kariapatti is located around $24 \mathrm{Km}$ in Tamil Nadu. It is situated near Madurai-Thuthookudi National Highway 45B. Kariapatti tower is just $2 \mathrm{Km}$ from National Highway in east direction shown in fig 1 . The tower shares other Antenna assemblies also and locations of WiMAX antenna assembly (left) and Radio Resource Unit (RRU) (right) are shown as inset. The antenna assembly is located at a height of $35 \mathrm{~m}$. The output power at antenna connector is set at $40 \mathrm{dBm}$ and antenna used has dual element system $(2 \mathrm{Rx} / 1 \mathrm{Tx})$ with gain of $17 \mathrm{dbi}$. The antenna orientations are set at $60^{\circ}-180^{\circ}-300^{\circ}$ respectively. The frequencies used are in of $5 \mathrm{MHz}$ bandwidth each and from $2.640 \mathrm{GHz}$ to 2.650 GHz. The system uses Time Division Duplexing, convolution turbo code and Adaptive Multiple Antenna.

\subsection{Measurement environment}

\subsubsection{Alpha Sector Direction}

The way of direction which is marked as Y goes towards few populated area. At around $0.065 \mathrm{~km}$ the $\mathrm{Rx}$ is in a close proximity to BTS results in a fall of signal shown in fig 9 by point A. At point $\mathrm{B}$ around $0.204 \mathrm{~km}$ the way is surrounded by few populated area comprising of maximum single storey buildings LOS exist between $\mathrm{Tx}$ and $\mathrm{Rx}$ and allow the signal to propagate with little suffering from diffraction, reflection, absorption and scattering. Around $0.204 \mathrm{~km}$ to $0.659 \mathrm{~km}$ on the left side of the way having many buildings stops the signal to reach the receiver results in fall of signal which is indicated by point B to C. D to E is inside the city even if LOS is available, the received signal undergoes deterioration/ improvement due to additional reflections and scattering by road and local moving traffic e.g. bus, taxi. At the distance around $1.205 \mathrm{~km}$ to $1.554 \mathrm{~km}$ again having number of buildings on left side causes poor LOS as shown in fig from E to F. On the way from $\mathrm{F}$ to $\mathrm{G}$ around $1.554 \mathrm{~km}$ to $1.974 \mathrm{~km}$ is a regular terrain with a few medium height trees which causes ups and down of signal. From $1.974 \mathrm{~km}$ towards National Highway at point $\mathrm{G}$ on the right side of the way are having a few populated areas the signal is reflected from the buildings and reaches the Rx. At the end of the way up to $2.5 \mathrm{~km}$ towards Madurai the Rx is on the National Highway45B shown by point $\mathrm{H}$. Field strength of signal decreases with increase in distance between BTS and Rx.

\subsubsection{Gamma Sector Direction}

The way of direction which is marked as X goes towards BTS away from Madurai-Thuthookudi National Highway 45B. The Kariapatti BS surrounded by moderately spaced one to two storey buildings with trees. The landscape is even and the road crosses area having a factory on the left side around a distance from $3.564 \mathrm{Km}$ to $3.394 \mathrm{~km}$, the signal is reflected from the building and reaches the receiver causes LOS which shown in the fig6 from point E to D. From a distance of 3.6 to $3.4 \mathrm{~km}$ is an open field area shown in fig from point D to C. Around $2.5 \mathrm{~km}$ towards BTS there is a regular terrain up to a distance of $1.58 \mathrm{~km}$ marked from $\mathrm{C}$ to $\mathrm{B}$ shows continuous fall of signal. The signal obtained at point B is quiet weak shows frequent NLOS. From point B to A around 1.5 to $0.103 \mathrm{~km}$ signal strength increases slowly as the distance between BTS and Rx is decreasing. Route trace of Kariapatti Base station is shown in fig 1. 
International Journal of Next-Generation Networks (IJNGN) Vol.6, No.2, June 2014

\subsubsection{Subscriber Station (SS) Setup}

An outdoor SS was chosen for the measurements. The SS, laptop, dongle and GPS all were mounted inside a vehicle. The Global Positioning System (GPS) is a space-based satellite navigation system that provides location and time information in all weather conditions, anywhere on or near the Earth where there is an unobstructed line of sight to four or more GPS satellites. A dongle is a small piece of hardware that attaches to laptop and that enables additional functions such as audio, video, data, or other services. On the roof of the vehicle an outdoor antenna was mounted to get maximum signal strength. The total height of the antenna was at $3 \mathrm{~m}$ which, on an average, was equal to height of average buildings in suburban areas and line of sight signal was mostly obtained. The output at the antenna connector was $23 \mathrm{dBm}$ and had a gain of 3 $\mathrm{dBm}$. The laptop was loaded with driver software for measurement of signal parameters and attached to a server. RF performances were also monitored at Access Service Network (ASN) Gateway for uplink parameters.

Subscriber substation is shown in fig.(2).

\section{RESULTS AND DISCUSSIONS}

All CINR, path loss exponent and path loss with distance, RSSI obtained for Gamma Sector are shown in figs 3, 4, 5 and 6 respectively and the corresponding values for Alpha Sector at figs 7, 8, 9 and 10. RSSI values were compared with COST-231 model, Hata model, Modified Hata model and path loss plotted with parameters applicable for sub-urban. It is observed that the path loss slope is much less compared to other three models with high initial LOS. Figs 4 and 8 give path loss exponents for Alpha and Gamma Sector respectively.

For Alpha sector, RSSI was better than $-70 \mathrm{dBm}$ up to a distance of $0.403 \mathrm{~km}$ shown in fig 9 marked by B. After which it drops from -80 to $-85 \mathrm{dBm}$ up to $0.72 \mathrm{~km}$ at C. From $\mathrm{C}$ to $\mathrm{E}$ it is observed to improve again to $-70 \mathrm{dbm}$ up to $1.268 \mathrm{~km}$. CINR varied between 15 to 25 up to 1.301 $\mathrm{km}$. RSSI is again varied between -70 to -85 up to $1.941 \mathrm{~km}$ and better than -70 dam at $1.941 \mathrm{~km}$ indicated from $\mathrm{E}$ to $\mathrm{G}$. CINR varied between 10 to $25 \mathrm{up}$ to $1.941 \mathrm{~km}$ and between 15 to 20 up to $2.443 \mathrm{~km}$. From G to H RSSI varied between -75 to -80 up to $2.442 \mathrm{~km}$, after which it drops to $90 \mathrm{dBm}$ at $2.564 \mathrm{~km}$. RSSI is observed to mostly varied between -70 to $-80 \mathrm{dBm}$ whereas CINR between 15 to 25 .

For Gamma Sector, RSSI varied between $-60 \mathrm{dBm}$ to $-95 \mathrm{dBm}$ up to a distance between 0.103 to $1.58 \mathrm{Km}$ marked from A to B which shows frequent drop of signal at point B and CINR is nearly 2.5 , after which the RSSI was observed to improved slowly up to a distance of $2.5 \mathrm{Km}$ and better than $-70 \mathrm{dBm}$ at point $\mathrm{C}$ and CINR is better than 20 . From point $\mathrm{C}$ to $\mathrm{D}$ it was observed to vary between -65 to $-80 \mathrm{dBm}$ up to $3.5 \mathrm{~km}$. CINR varied between 25 to 10 .

Observation of Alpha Sector and Gamma Sector were regular for terrain. For Gamma Sector there was a continuous open field area up to several $\mathrm{kms}$ where direct signal is received by the receiver which affects RSSI and CINR. The drop of signal shown in fig (6) is indicated by B which shows the rapid signal drop. For Alpha Sector when the path loss is plotted against distance it was shown that path loss increased as the distance between the Tx and Rx is increased hence shows good results for RSSI and CINR.

The rate of propagation path loss is plotted against distance shown by the path loss exponent. If the path loss exponent value is 2 , then the environment propagation characteristic is close to free space propagation. Overall path loss exponent $(\gamma)$ for Alpha Sector was 2.351 and fading $(\sigma)$ 5.20415 fig (12); the corresponding values for Gamma Sector were 2.196 and 6.93145 fig (11) respectively. 
International Journal of Next-Generation Networks (IJNGN) Vol.6, No.2, June 2014

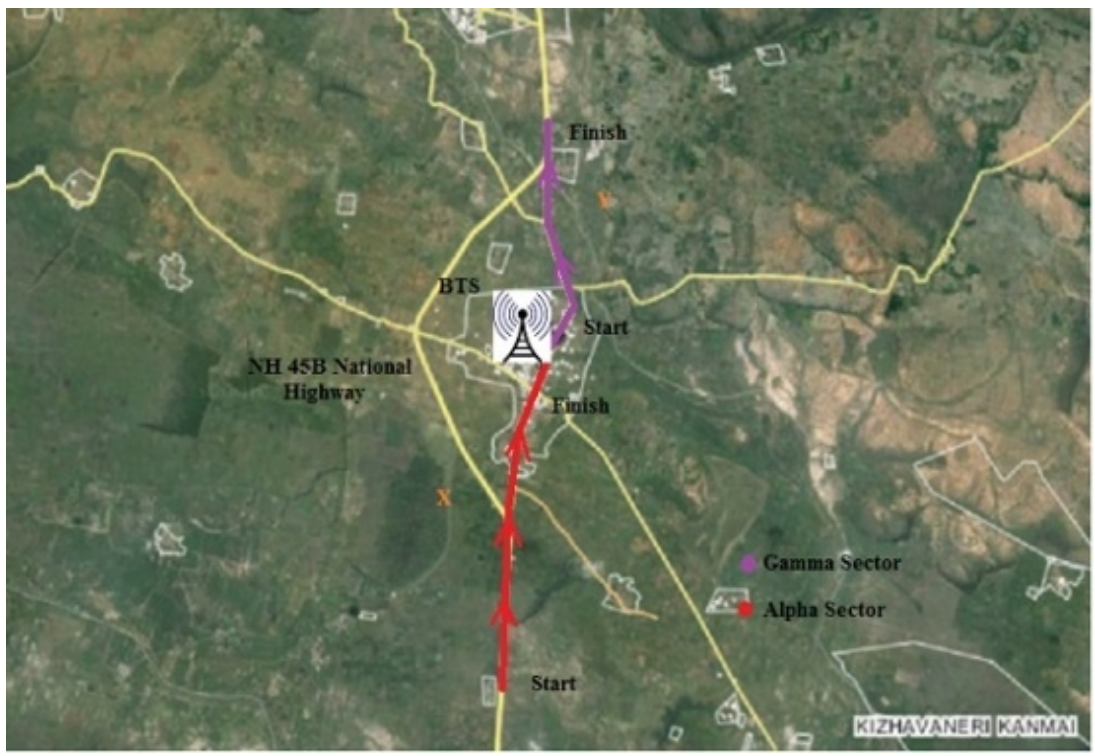

Fig 1: Kariapatti BS (red) with. $\mathrm{X}$ and $\mathrm{Y}$ route towards north

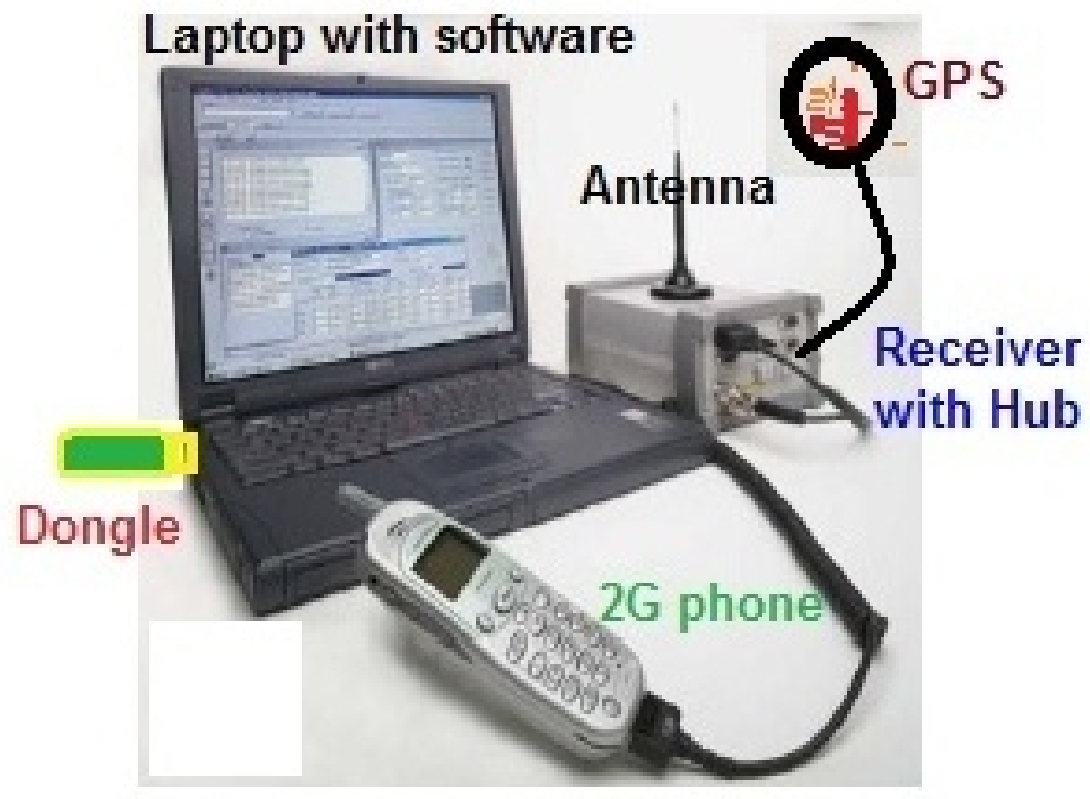

Fig 2: Subscribers substation 
International Journal of Next-Generation Networks (IJNGN) Vol.6, No.2, June 2014

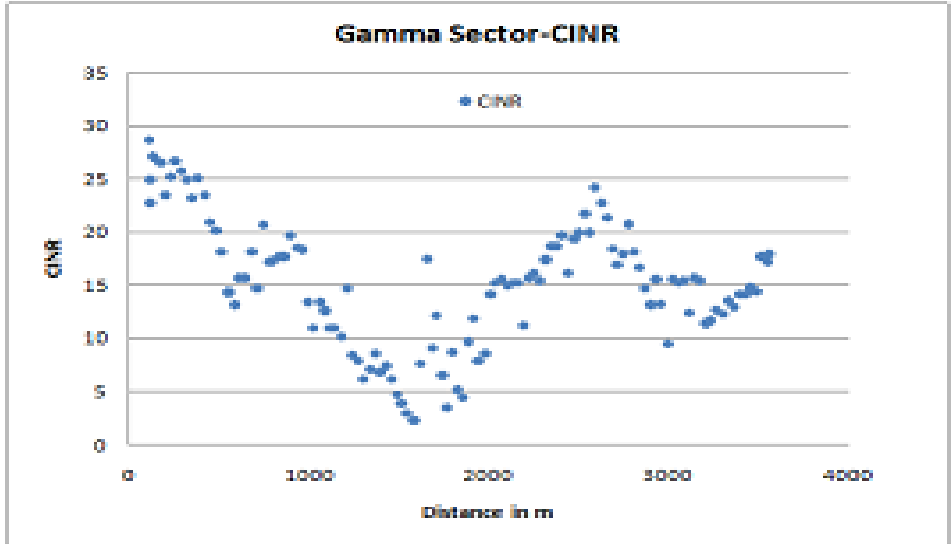

Fig 3: Gamma Sector CINR

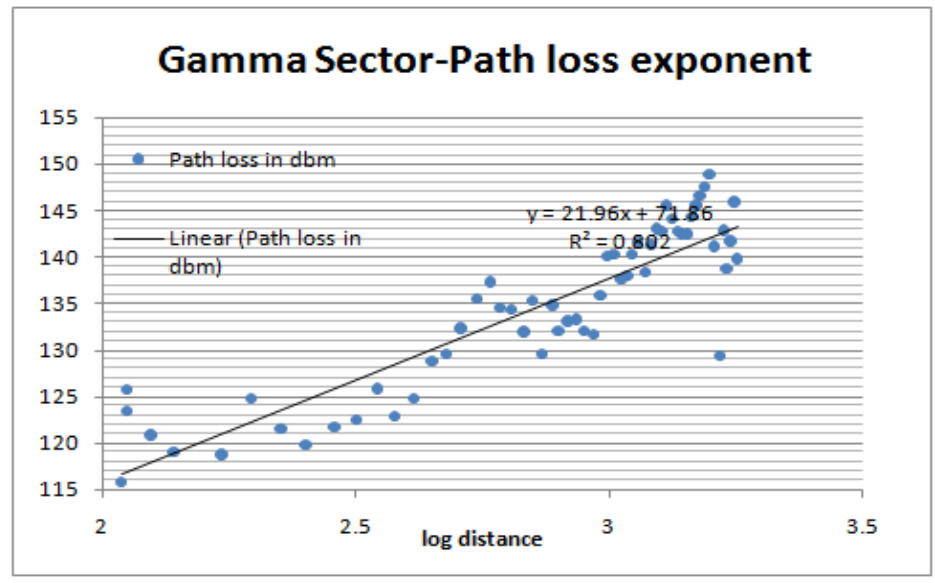

Fig 4: Gamma Sector Path loss exponent

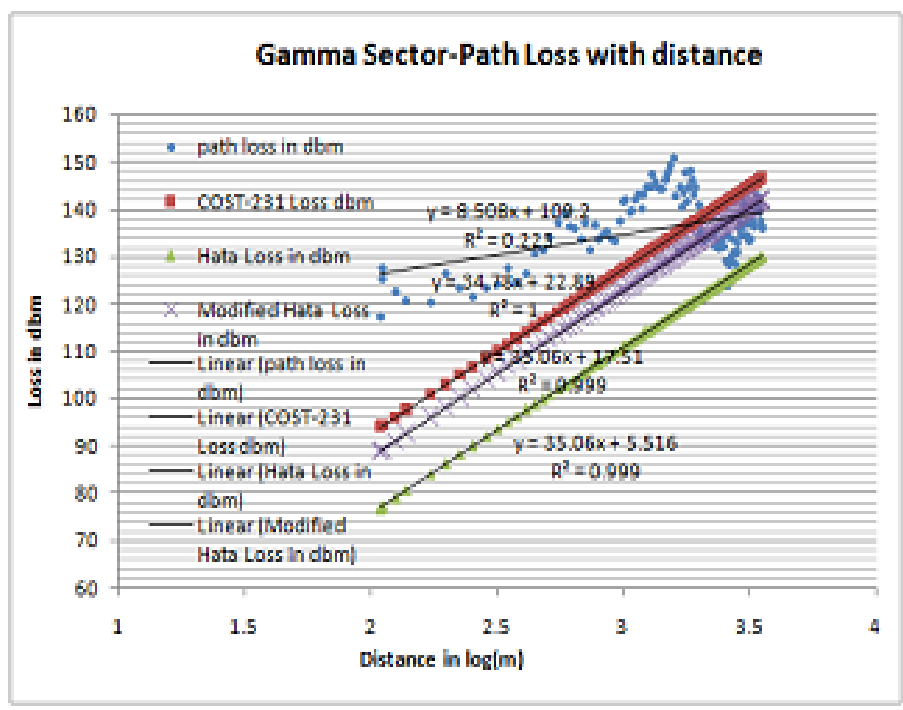

Fig 5: Gamma Sector Path loss with distance 
International Journal of Next-Generation Networks (IJNGN) Vol.6, No.2, June 2014

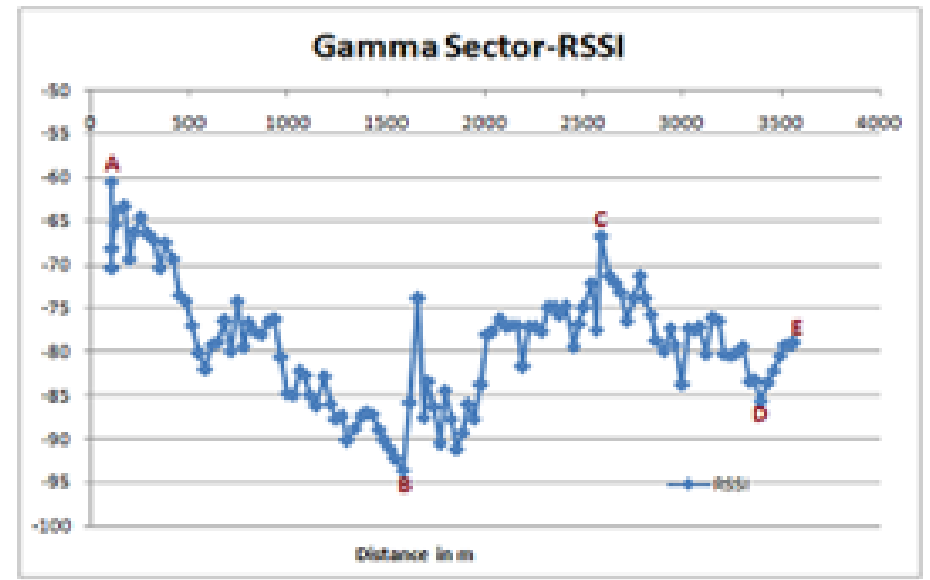

Fig 6: Gamma Sector RSSI

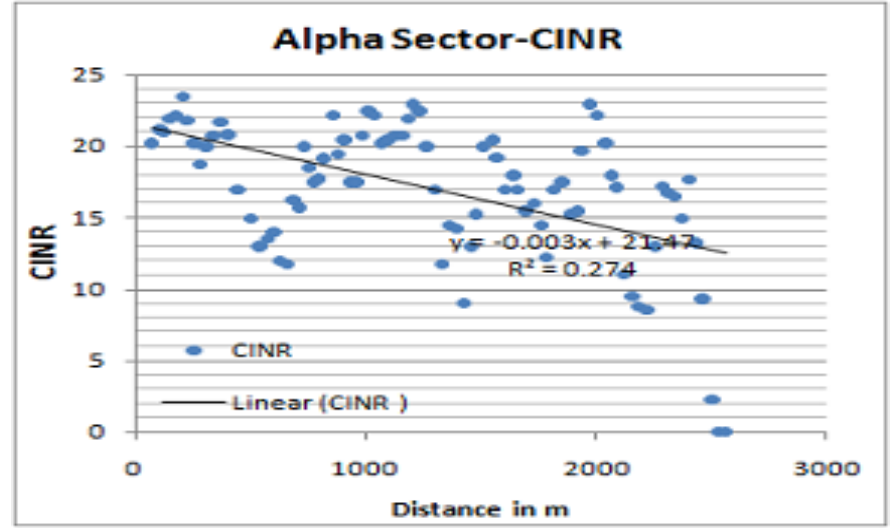

Fig 7: Alpha Sector CINR

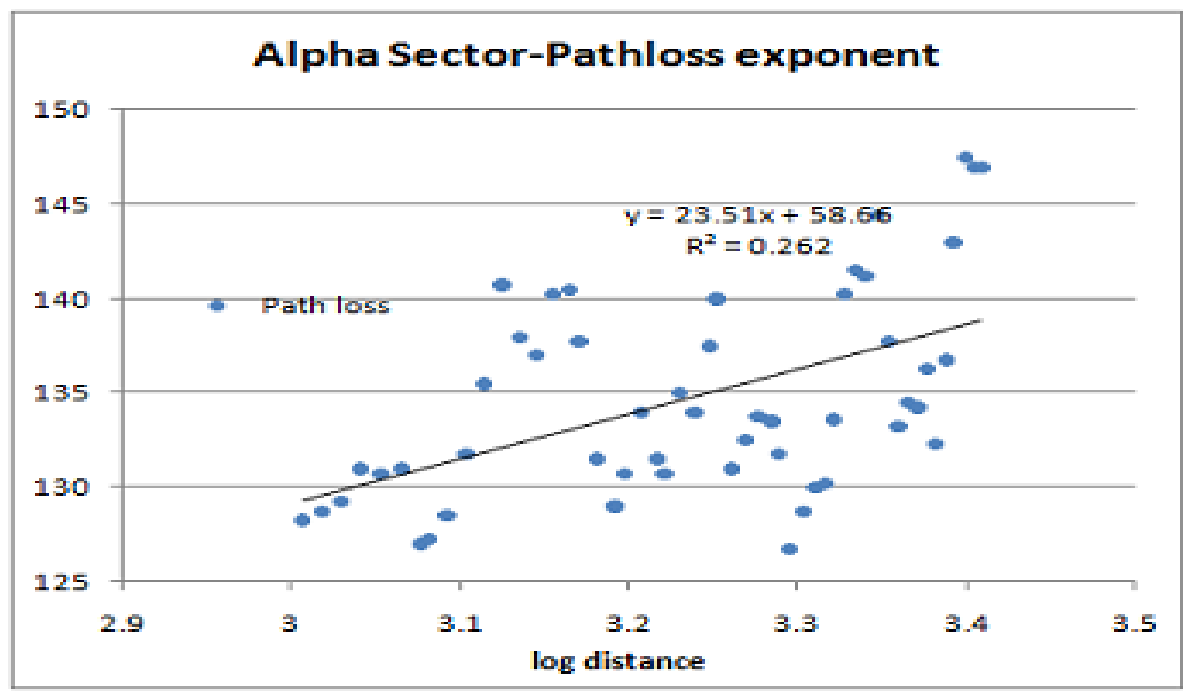

Fig 8: Alpha Sector Path loss exponent 
International Journal of Next-Generation Networks (IJNGN) Vol.6, No.2, June 2014

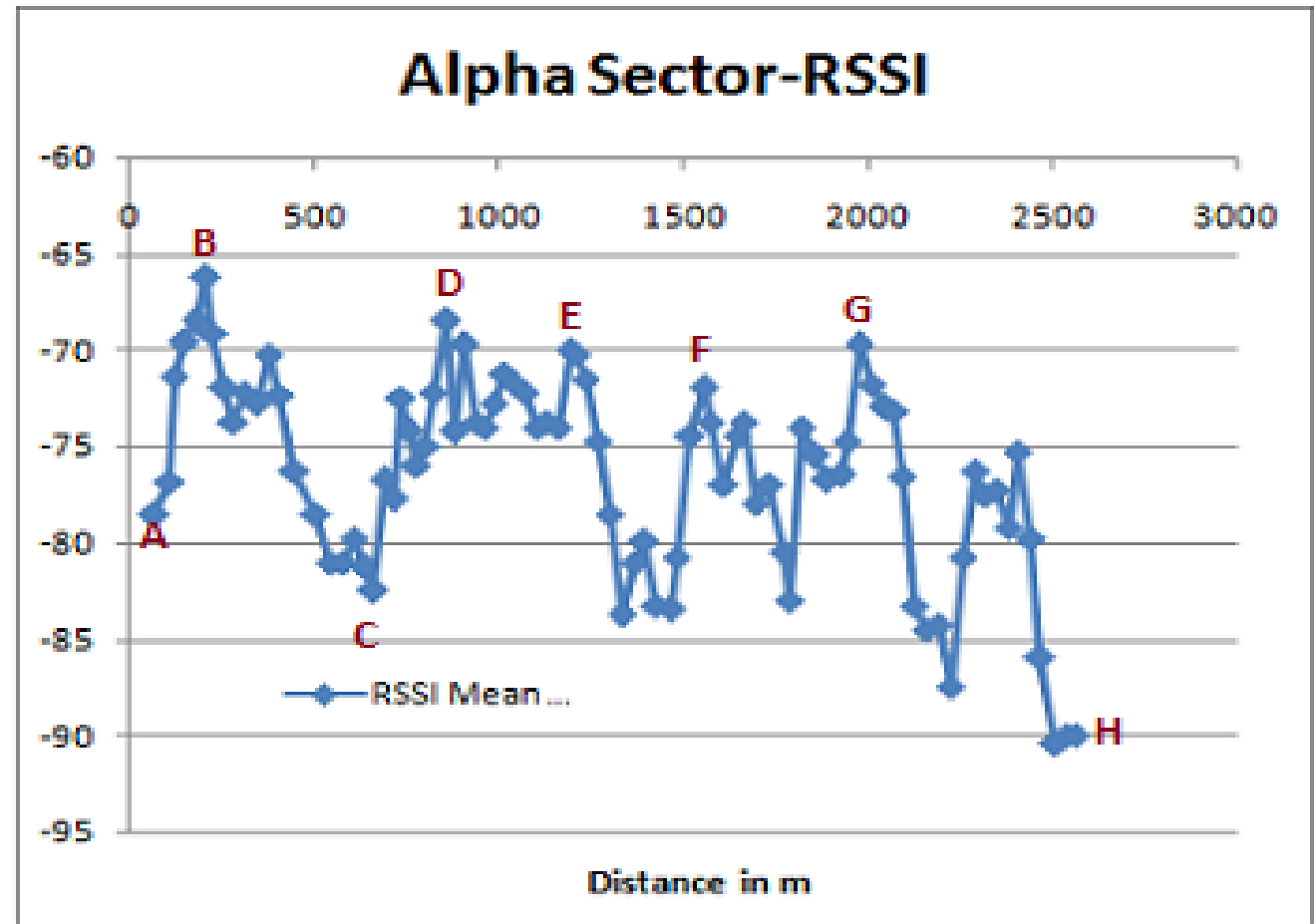

Fig 9: Alpha Sector RSSI

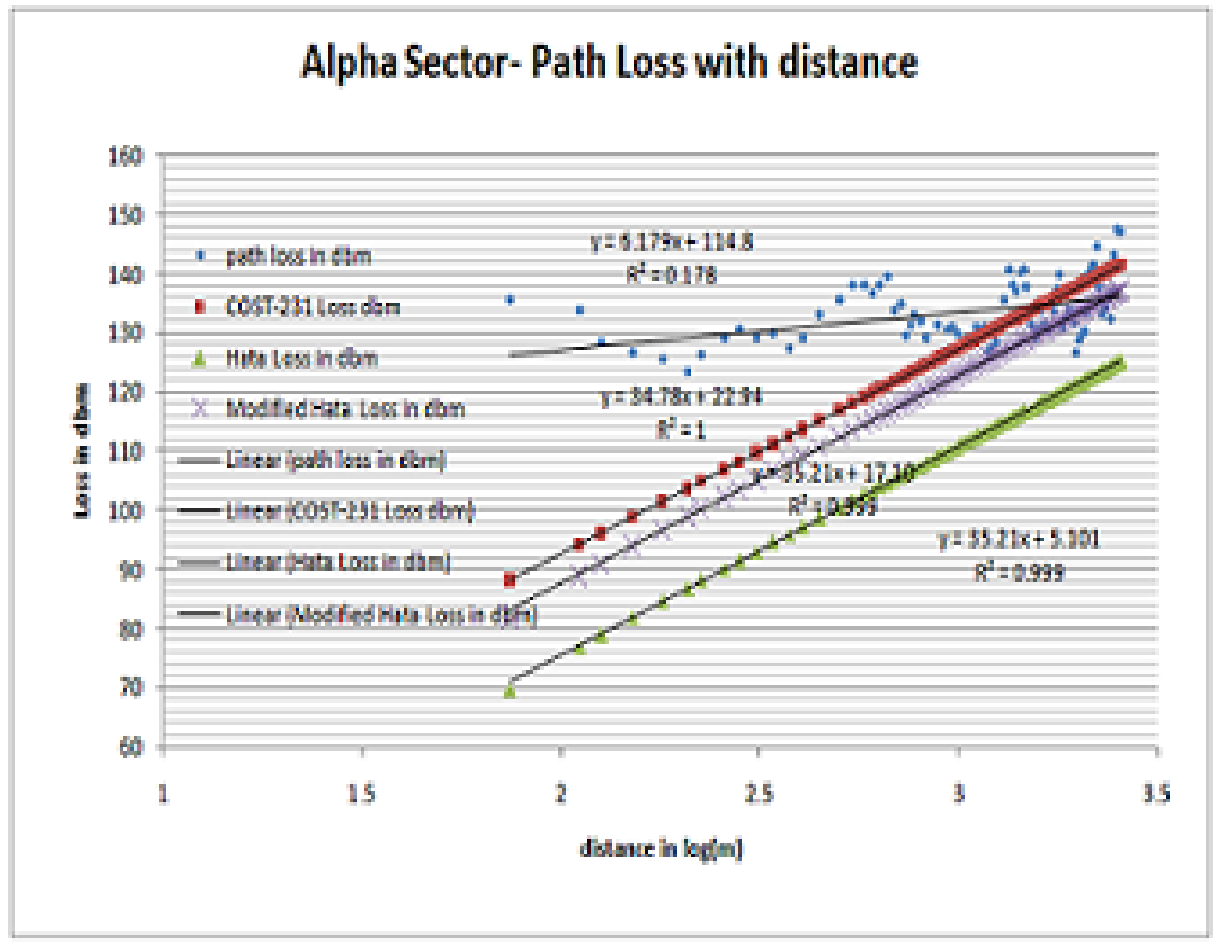

Fig 10: Alpha Sector Path loss with distance 
International Journal of Next-Generation Networks (IJNGN) Vol.6, No.2, June 2014

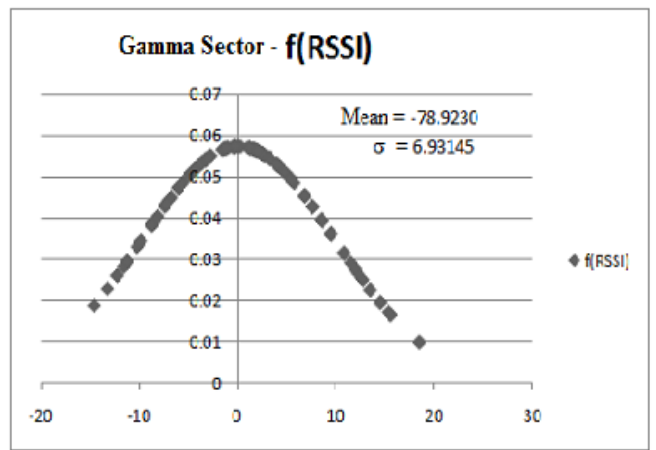

Fig 11: Signal strength distribution and Rayleigh fading factor estimation for Gamma Sector.

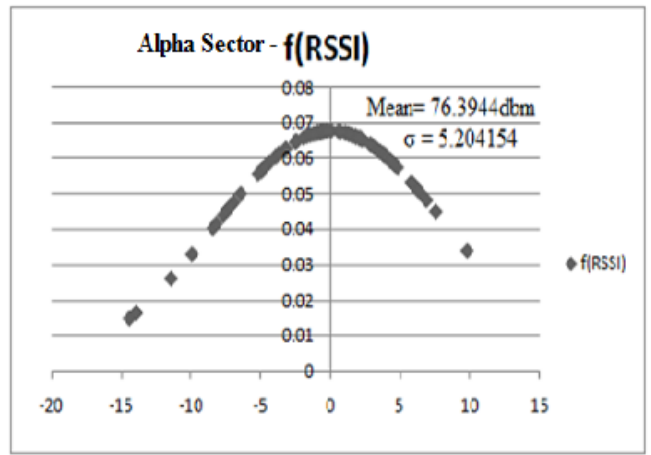

Fig 12: Signal strength distribution and Rayleigh fading factor estimation for Alpha Sector

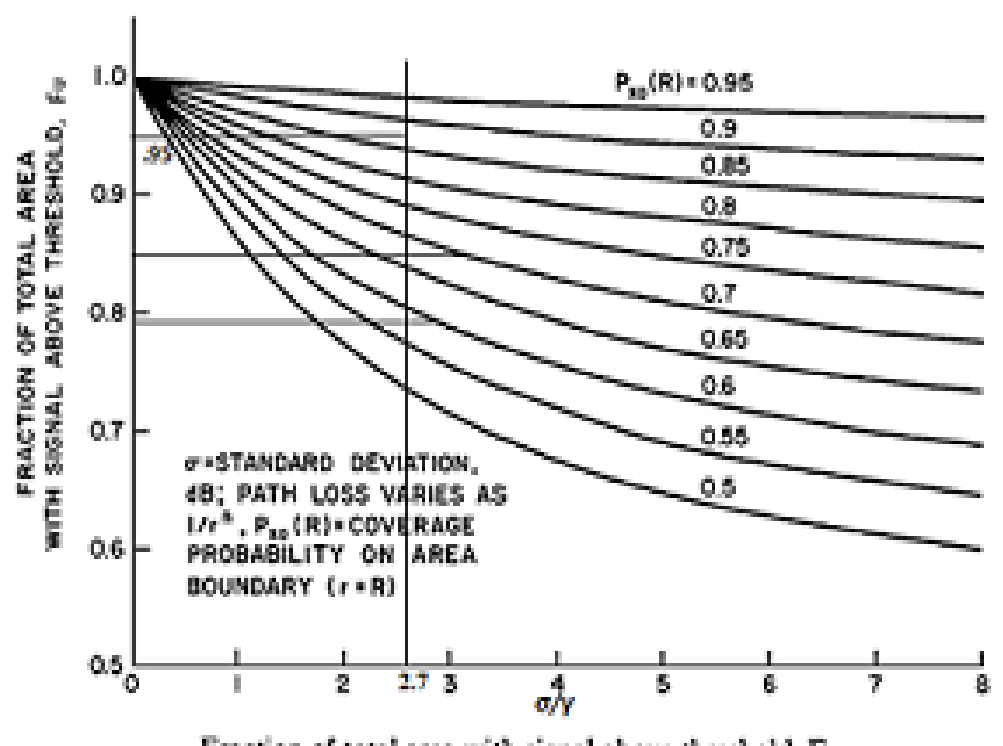

Fraction of total area with signal above threshold, $F_{w}$

Fig:13 Jakes graph

\section{CONCLUSION}

The obtained value of RSSI is higher than the calculated value which lead to overall value of $\gamma<2$ whereas for free space where $\gamma$ is equal to 2 . Low $\gamma$ value indicates better coverage than predicted by all models used by planning tools. This observation is similar to GSM as obtained in earlier observations. However this situation continued up to $1 \mathrm{Km}$ after which nearly free space propagation was observed. The $\sigma / \gamma$ value was observed as 2.6850 which is an average obtained from above path loss exponent $(\gamma)$ for Alpha Sector are 2.351 and fading $(\sigma) 5.20415$ fig (12); the corresponding values for Gamma Sector are 2.196 and 6.93145 fig (11) respectively. The Cell edge probability and corresponding area coverage probability can be stated with better degree of confidence level using Jakes Graph; however RSSI was observed to be nearly $-90 \mathrm{dBm}$ at point $\mathrm{B}$; this drop of signal is shown in fig (6) where Jakes Graph is nearly conical as in fig (13). If -85 $\mathrm{dBm}$ is considered as threshold with a mean value of RSSI as $-78 \mathrm{dBm}$ as in fig (11) and average 
International Journal of Next-Generation Networks (IJNGN) Vol.6, No.2, June 2014

$\sigma / \gamma=2.6850$, we get radius coverage probability as 0.87 using equation (2). From fig (13) with 0.87 as $P x_{0}(\mathrm{R})$ profile, the corresponding area coverage probability is $\sim 95 \%$ for a radius $\sim 2500 \mathrm{~m}$ as evident from fig (8) and fig (9).Jakes graph and the graphs drawn on the basis of this experiment are sufficient for cell planning of an area.

\section{REFERENCES}

[1] Gopal Chandra Manna, Bhavana Jharia "Mobile WiMAX Coverage Evaluation for Rural Areas of India" Advanced Communication Technology (ICACT),13th International Conference on 13-16 Feb. 2011 at Seoul (India).

[2] S.K. Sarkar and G.C. Manna, "Comparison Among GSM, CDMA AND WIMAX As Fast Track Access Network For Fourth Generation Mobile Terminal", National Convention and Seminar on Mobile Spectrum: Issues and Challenges to Engineers- Institution of Engineers (India) at Jabalpur, on 24th and 25th October, 2009

[3] S.K. Sarkar and G.C. Manna, "Performance Evaluation of IEEE 802.16 based System in Sub-urban Area", Telecommunications, Vol-59, Issue 2, March-April 2009.

[4] Mardeni. R, T.Siva Priya, "Optimized COST-231 Hata Models for WiMAX Path Loss Prediction in Suburban and Open Urban Environments" Vol. 4, No. 9; September 2010.

[5] Taimoor Abbas, Johan Karedal and Fredrik Tufvesson, "A Measurement Based Shadow Fading Model for Vehicle-to-Vehicle Network Simulations” February, 2014 - IEEE Xplore digital library.

[6] Md. Didarul Alam1 and Md. Rezaul Huque Khan2, " Comparative Study of Path Loss Models of WiMAX at $2.5 \mathrm{GHz}$ Frequency Band" in International Journal of Future Generation Communication and Networking Vol. 6, No. 2, April, 2013.

[7] R. Mardeni and K. F. Kwan "Optimization of HATA Propagation Prediction Model In Suburban Area in Malaysia” Progress In Electromagnetics Research C, Vol. 13, 91-106, 2010.

[8] P.Saveeda, E.Vinothini, Vardhi Swathi and K.Ayyappan, "Received Signal Strength (RSS) Calculation for GSM Cellular System at BSNL Pondicherry using Modified HATA Model”in IJSETR Volume 2, Issue 1, January 2013.

[9] Johan Karedal, Alexander Paier, Fredrik Tufvesson and Andreas F. Molisch, "Path Loss Modeling for Vehicle-to-Vehicle Communications" IEEE transactions on vehicular technology, Vol. 60, no. 1, January 2011.

[10] Noman Shabbir1, Muhammad T. Sadiq2, Hasnain Kashif3 and Rizwan Ullah4,"Comparison of Radio Propagation Models For Long Term Evolution (LTE) Network” International Journal of NextGeneration Networks (IJNGN) Vol.3, No.3, September 2011.

[11] Hennann Lipfert, Alois Zistler, Aylin Vogl, Madeleine Keltsch, "Performance Testing in a WiMAX-Pilot at the Institute fur Rundfunktechnik", April 8, 2009 - IEEE Xplore digital library.

[12] N. Coelho, N. Cabral, A. Pereira, A. Rocha and A. Navarro, "Mobile WiMAX Field Trials in a Suburban Area",IEEE Xplore Digital Library.

[13] Mukesh Kumar, Vijay Kumar, Suchika Malik, "Performance and Analysis of Propagation Models for Predicting RSS for Efficient Handoff" International Journal of Advanced Scientific and Technical Research Issue2, volume 1, February 2012.

[14] Chhaya Dalela , "Radio Measurements in the WiMAX Band of $2.3 \mathrm{GHz}$, in Coastal Zone for Different Transmitting Antenna Heights" in IJEAT, Volume-1, Issue-5, June 2012.

[15] Hongguang Zhang1, Mohammed Boutabia2, Hang Nguyen2, Noël Crespi2, Ai-Chun Pang3, Liang Zhou4, Jianming Weil"Mobile WiMAX Field Trial Test through Multimedia Performance Evaluation" Author manuscript, published in "EURASIP Journal on Wireless Communications and Networking (2012)."

\section{Authors}

Pratibha Maina has completed her Bachelor of Engineering degree in Electronics and Communication Engineering from Samrat Ashok Technological Institute ,Vidisha, India. She is currently an Master of Engineering (Communication system) student at Jabalpur Engineering College (M.P.), India. Her area of interest is Wireless Communication.

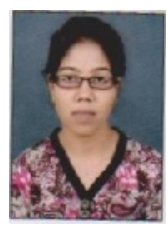


International Journal of Next-Generation Networks (IJNGN) Vol.6, No.2, June 2014

Dr. Gopal Chandra Manna had done Ph.D. from Electronics and Telecommunications Engineering of Jadavpur University, Kolkata. He had both graduated and post graduated in Radio Physics and Electronics Engineering from University of Calcutta and undergone trainings at Beijing University of Post and Telecom China in 1990 and DARTEC, Montreal, Canada in 1999. He is working as Senior General Manager, Inspection Circle, BSNL, Govt. of India. GSM, CDMA, WCDMA and WiMAX radio access are his area of research. An one week course on Quality of Service Monitoring at ICTA, Mauritius as International Expert through CTO, London during 2010 has been developed and conducted by him. From 1997 to 2002, he had worked as Deputy General Manager in Telecommunication Training Centre of DoT and installed live training node for Internet Service Provider(ISP). He had conducted training programs for participants from Asia Pacific Telecommunications (APT) and Sri Lankan Telecom and seminars with international experts of UNDP/ITU.

Namarata Sahayam received the Bachelors Degree in Electronics and Communication Engineering from Government Engineering College, Rewa, India in 2003 and Mtech in Digital Communication from RGPV, Bhopal in 2008. She is currently working as an Assistant Professor in Department of Electronics and Communication Engineering of Jabalpur Engineering College (M.P.), India. Her research of interest is in the field of Wireless Communication and Signal Processing. 